\title{
Non-Invasive Nasal Hydromorphone with High Bioavailability for Rapid Onset and Non-Dissociative Acute Pain Control: A Feasibility Study
}

Cunningham $\mathbf{G}^{1}$ and Maggio $\mathrm{ET}^{2^{*}}$

${ }^{1}$ Accelevation Bio, LLC, Corvallis, OR 97330, USA

${ }^{2}$ Aegis Therapeutics LLC, 11770 Bernardo Plaza Ct., Ste 353 San Diego, CA 92128, USA

\begin{abstract}
Aim: To test the hypothesis that intranasal hydromorphone could mimic IV administration parameters for use in acute pain situations such as battle field injury, EMS first response and breakthrough cancer pain.

Methods: A single healthy volunteer was recruited to a monocentric, open label, randomized, four-way crossover pharmacokinetic study, with 7 days washout period between treatments (more than 70 times the terminal elimination half-life). The use of a single subject minimized the effect of person to person variability in metabolism. For small molecule drugs (i.e., MW<1,000 Daltons) nasal bioavailability in the presence of alkylsaccharide absorption enhancers is predominantly a function of molecular weight and is expected to be high. Unexpected impediments to nasal delivery are likely due to local mucosal irritation or vasoconstriction, which can reduce bioavailability. According to an analysis of FDA data by eHealthMe, of 18,420 people reported to have side effects when taking hydromorphone, only 1 person reported vasoconstriction.

The subject received $2 \mathrm{mg}$ oral hydromorphone vs. 3 different formulations of $2 \mathrm{mg}$ intranasal hydromorphone administered using a $100 \mu \mathrm{l}$ Aptar multidose spray pump (Aptar Group, Crystal Lake, IL). Hydromorphone concentrations were evaluated by HPLC-MS/MS. Bioavailability was calculated using trapezoidal methodology to determine area under the curve.

Results and conclusion: Moderate euphoria was observed for all dosage forms, nasal and oral. Oral concentrations were fairly low at all reportable time periods, with $T_{\text {max }}$ at minute 60 and $C_{\text {max }} 1.5 \mathrm{ng} / \mathrm{mL}$. All intranasal formulations exhibited a greatly improved $T_{\max }$ of 10 minutes and improved $\mathrm{C}_{\max }$ values. IN-3 had a significantly better $\mathrm{C}_{\text {max }}$ value of $6.6 \mathrm{ng} / \mathrm{ml}$ respectively and drug effect was noted as early as minute 1 , experienced as a moderate euphoria which lasted until minute 120, then tapering off. We believe the proprietary formulations of intranasal hydromorphone should be further investigated and developed.
\end{abstract}

Keywords: Nasal delivery; Hydromorphone; Acute pain control; Pharmacokinetics; Rapid onset; Non-dissociative; Battlefield injury, EMS first responders; Breakthrough cancer pain; Intravail

Abbreviations: MW: Molecular Weight; BA: Bioavailability; HPLCMS/MS: High-Performance Liquid Chromatography Coupled to Tandem Mass Spectrometry; $\mathrm{C}_{\max }$ : Maximum Plasma Concentration; $\mathrm{T}_{\max }$ : Time to Reach the Maximum Plasma Concentration; $\mathrm{AUC}_{0 \text {-last }}:$ Area under Curve of Plasma Concentration until the Last Concentration Observed; IV: Intravenous; SC: Subcutaneous; IM: Intramuscular

\section{Introduction}

Achieving pain control in acute pain situations such as battlefield injury, EMS first responders, emergency department cases and breakthrough cancer pain has quite often proved challenging [1-3]. Although opioid medications are effective at acute pain relief, current delivery methods can fail or prove inadequate in many circumstances. Oral delivery of opioids can delay the onset of relief due to slow absorption and a large hepatic first-pass effect and is ineffective for emetic patients. Intramuscular injection is slightly faster than oral delivery, but has high variability in absorption depending on patient characteristics, can result in tissue depot effects leading to possible under or overdosing and is less effective in shock situations when blood flow to peripheral tissues is limited. Intravenous administration is the preferred method of opioid delivery, but requires trained personnel to initiate and proves challenging in situations where venous access is not available due to shock, hypovolemia, or venous injury from frequent IV medication use.

There exists a need for a better delivery method for opiate pain medications in these situations. Various EMS, military and other healthcare organizations have solicited ideas for improving pain control in acute pain scenarios. While opiate medications are undeniably the most effective pain control medications, their limitations exist within the route of administration.

The non-ionic alkylsaccharide surfactant absorption enhancers known collectively as Intravail excipients have been demonstrated to substantially increase systemic absorption (increased $\mathrm{C}_{\max }$ and bioavailability) and speed of drug uptake (shortened $\mathrm{T}_{\max }$ ) [4]. They are chemically synthesized molecules that are metabolized to $\mathrm{CO}_{2}$ and $\mathrm{H}_{2} \mathrm{O}$ [5]. Typical Intravail excipients include alkyl glycosides such as decyl-, dodecyl- and tetradecyl-maltoside and long chain alkyl esters such as sucrose mono-, di- and tri-alkyl esters with alkyl chains ranging from $\mathrm{C} 10$ to $\mathrm{C} 18$. Intravail excipients allow intranasal delivery of small molecule, peptide, protein and non-protein macromolecular drugs [6-8] having molecular weights up to and in excess of 25,000 Daltons, with bioavailabilities in excess of $50 \%$ compared to subcutaneous (SC)

*Corresponding author: Maggio ET, Aegis Therapeutics LLC, 11770 Bernardo Plaza Ct., Ste 353 San Diego, CA 92128, USA, Fax: 858-618-1441; Tel: 858-6181400; Ext: 101; E-mail: emaggio@aegisthera.com

Received November 21, 2017; Accepted January 10, 2018; Published January 20, 2018

Citation: Cunningham G, Maggio ET (2018) Non-Invasive Nasal Hydromorphone with High Bioavailability for Rapid Onset and Non-Dissociative Acute Pain Control: A Feasibility Study. J Bioequiv Availab 10: 014-017. doi: 10.4172/jbb.1000369

Copyright: @ 2018 Cunningham G, et al. This is an open-access article distributed under the terms of the Creative Commons Attribution License, which permits unrestricted use, distribution, and reproduction in any medium, provided the original author and source are credited. 
injection. The permeation effectiveness is largely a function of molecular weight of the drug. For drugs under 1000 Daltons, bioavailabilities approach $100 \%$ compared to IV or SC administration. For example, the metered nasal spray Intravail formulation of diazepam (MW=284.7 g/ mol) achieves $96 \%$ absolute bioavailability [9] and the Intravail-based sumatriptan $(\mathrm{MW}=295.4 \mathrm{~g} / \mathrm{mol})$ formulation achieves bioavailability in the $90 \%$ range compared to SC injection [10]. The molecular weight of hydromorphone is $285.3 \mathrm{~g} / \mathrm{mol}$ and based on MW, in the absence of any idiosyncratic properties, the bioavailability would be expected to be similar.

\section{Rationale for selection of hydromorphone}

Although many medications have shown promise in relieving chronic pain, opiates remain the most effective medications for acute pain (short of full anaesthesia). Of the opiates in current clinical practice, the most commonly used and most effective for acute pain are morphine, fentanyl and hydromorphone. Morphine has historically been the benchmark medication for acute pain and has slowly fallen out of favour due to its side effect profile, but is still used in some situations. Fentanyl and hydromorphone, both synthetic opiates, are far stronger than morphine (50X and $7 \mathrm{X}$, respectively), carry a more desirable side effect profile (less nausea, respiratory depression, etc.) and seem to have better affinity for certain opioid receptors in the brain which modulate pain.

Despite the differences in equianalgesic strength between fentanyl and hydromorphone, hydromorphone has emerged as the preferred opiate to consider for reformulation. Hydromorphone has a similar side effect profile to fentanyl, but clinical studies have suggested lesser respiratory depression, pruritus and allergic reactions compared with fentanyl; although hydromorphone may have a slightly increased propensity to cause hypotension. Hydromorphone has a slightly longer duration of action than fentanyl, decreasing the number of doses needed per day or re-dosing prior to receiving other interventional care. Patient derived data has also shown a difference in pain control effectiveness favouring hydromorphone [11], possibly due to its affinity for and reaction with certain opioid receptors in the brain. Hydromorphone is also non-dissociative, potentially allowing patients or soldiers to self-extract, or cooperate with first responders in extraction from the danger zone and to communicate more coherently with caregivers.

The route of administration was also considered. Oral administration was eliminated due to the large decrease in bioavailability related to hepatic first pass effect. IV administration was eliminated due to the issues surrounding the requirement for trained personnel to initiate intravenous access, a primary consideration for the organizations addressed above. Intramuscular (IM) injection and nasal administration were both considered, however, the issue of tissue depot and delay in medication effect eventually eliminated IM injection.

\section{Materials and Methods}

\section{Formulation}

Several small pharmacokinetic studies have shown evidence of effective absorption and increased bioavailability of intranasal hydromorphone versus oral hydromorphone [12]. In an effort to increase this absorption and bioavailability, hydromorphone was paired with a novel excipient, dodecyl maltoside (Intravail'-A3), which has been shown to increase absorption, bioavailability and speed of onset compared with other common excipients. In total, 3 preparations of hydromorphone were created with Intravail" using different buffering constituents at differing pH's and tested to assess pharmacokinetic parameters. These formulations were all prepared to provide a concentration of $2 \mathrm{mg}$ hydromorphone per $100 \mu \mathrm{l}$ nasal spray volume. The compositions are summarized in Table 1.

\section{Clinical protocol}

A single subject was selected to test both oral hydromorphone and the 3 formulations of intranasal hydromorphone in 4-hour trials. The subject was given either one $2 \mathrm{mg}$ oral tablet of hydromorphone or one $2 \mathrm{mg}$ intranasal dose of hydromorphone at each trial.

A venous catheter was inserted into the subject's non-dominant arm for sampling. Immediately prior to administration and then at 2.5 minutes, 5 minutes, 7.5 minutes, 10 minutes, 15 minutes, 20 minutes, 30 minutes, 1 hour, 2 hours and 4 hours post administration, the investigator drew approximately $3 \mathrm{ml}$ of fluid from the cannula for disposal, then extracted $5 \mathrm{ml}$ of blood into a spray silica coated red topped vacutainer, labelling with the time period drawn and kept at room temperature for at least 30 minutes until the blood clotted. The subject's venous cannula was then flushed with approximately $3 \mathrm{ml}$ saline. Routine blood pressure monitoring, pulse, body temperature and subjective reports of drug effects and side effects were collected during the study. No significant adverse events were reported. Vital signs remained within normal limits throughout the trial periods. Subjective reports of drug effects were noted for each formulation.

\section{Sample preparation}

Blood samples were centrifuged at $3000 \mathrm{rpm}$ for 10 minutes at room temperature. Aliquots of at least $1.5 \mathrm{ml}$ of serum were decanted into marked tubes and refrigerated within 20 minutes of centrifugation, until eventual analysis.

\section{Analytical assays}

Once all samples were taken, they were transported under refrigeration via courier to the analytical laboratory. Hydromorphone serum levels were determined by NMS Laboratories, Willow Grove, PA, (www.nmslabs.com), accredited by the College of American Pathologists, using a validated High-Performance Liquid Chromatography/Tandem Mass Spectrometry (LC-MS/MS) assay [13]. Data were reported to the sponsor within 7 days of analysis.

\section{Results}

\section{Pharmacokinetics}

Concentrations were analysed and reported in $\mathrm{ng} / \mathrm{ml}$ at each time period collected (Figure 1). Oral concentrations were fairly low at all reportable time periods, with $\mathrm{T}_{\max }$ at minute 60 and $\mathrm{C}_{\max } 1.5 \mathrm{ng} / \mathrm{ml}$. Intranasal formulation $\mathrm{IN}-1$ was noted to greatly improve $\mathrm{T}_{\max }$ (minute 10 ) with a slightly better $C_{\text {max }}(2.4 \mathrm{ng} / \mathrm{ml})$. Intranasal formulation $I N-2$ had an identical $\mathrm{T}_{\max }$ (minute 10) with a significantly better $\mathrm{C}_{\max }(5.7$ $\mathrm{ng} / \mathrm{ml}$ ). Intranasal formulation IN-3 also had an identical $\mathrm{T}_{\max }$ (minute 10 ) with a significantly better $C_{\text {max }}(6.6 \mathrm{ng} / \mathrm{ml})$.

\begin{tabular}{|c|c|c|c|}
\hline $\begin{array}{c}\text { Nasal } \\
\text { formulations }\end{array}$ & Buffer & pH & $\begin{array}{c}\text { Absorption } \\
\text { enhancer }\end{array}$ \\
\hline IN-1 & 20 mM Sodium acetate & 5.0 & None \\
\hline IN-2 & Phosphate (PBS) & 6.0 & $\begin{array}{c}0.2 \% \text { Dodecyl } \\
\text { maltoside }\end{array}$ \\
\hline IN-3 & Phosphate (PBS) & 6.5 & $\begin{array}{c}0.2 \% \text { Dodecyl } \\
\text { maltoside }\end{array}$ \\
\hline
\end{tabular}

Table 1: Composition of nasal formulations. 
Citation: Cunningham G, Maggio ET (2018) Non-Invasive Nasal Hydromorphone with High Bioavailability for Rapid Onset and Non-Dissociative Acute Pain Control: A Feasibility Study. J Bioequiv Availab 10: 014-017. doi: 10.4172/jbb.1000369

Both Intranasal formulations $\mathrm{IN}-2$ and $\mathrm{IN}-3$ saw higher concentrations at the first draw (minute 2.5) than that seen with the oral tablet, confirming the subjective observations by the test subject on timing of drug effect. Both formulations showed near- $\mathrm{C}_{\max }$ concentrations at minutes 5 and 7.5. Duration of action was similar for all tested doses and confirmed from concentrations at the time periods noted. No appreciable blood concentration was noted at minute 240 (Figure 1).

Bioavailability was calculated using trapezoidal methodology to determine area under the curve (Table 2). Because little data exists on intranasal BA, an average of published data on oral BA $[13,14]$ was used to extrapolate relative nasal bioavailability. The available published estimates include $50.7 \% \pm 29.8 \%$ [14] and $24 \% \pm-21 \%$ [14] yielding an average oral BA of $37.5 \%$.

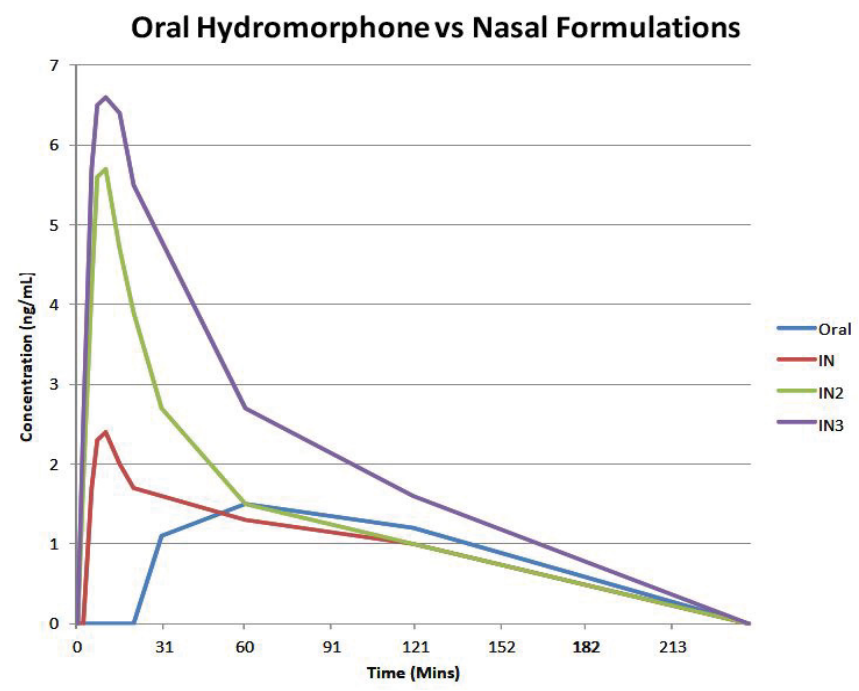

Figure 1: Comparison of $2 \mathrm{mg}$ oral hydromorphone vs. 3 different formulations of $2 \mathrm{mg}$ intranasal hydromorphone with serum concentrations collected at various time intervals in a single subject study.

\section{Subject's report}

Oral tablet effects of drug were reported at minute 34 , experienced as slight euphoria increasing until minute 120, then tapering off. Slight nausea was experienced from minute 120 until the end of the study arm.

Nasal formulation IN-1 was taken without report of any unpleasant nasal sensation. A bitter taste in the back of the throat was experienced at minute 5. Drug effect was noted at minute 4 , experienced as a moderate euphoria which lasted until minute 120, then tapering off. Slight nausea was experienced from minute 90 until the end of the study arm.

Nasal formulation IN-2 was taken with report of slight nasal burning, rated a 1 on the standard pain scale. A bitter taste in the back of the throat was experienced at minute 5 . Drug effect was noted slightly after minute 1, experienced as a moderate euphoria which lasted until minute 120, then tapering off. Slight nausea was experienced from minute 100 until the end of the study arm.

Nasal formulation IN-3 was taken with report of slight nasal burning, rated a 1 on the standard pain scale. A bitter taste in the back of the throat was experienced at minute 5. Drug effect was noted at minute 1 , experienced as a moderate euphoria which lasted until minute 120, then tapering off. Slight nausea was experienced from minute 90 until the end of the study arm.

An average of published data on oral BA [14,15] was used to extrapolate relative nasal bioavailabilities of the three nasal formulations. In the two-published human oral studies cited, it is likely that the oral bioavailability values varied due to differences in hepatic metabolism or other subject-group specific factors. Nevertheless, the BA for intranasal formulations IN-2 and IN-3 were significantly better than the $\mathrm{BA}$ of oral hydromorphone based on the individually reported oral BA values or the average of the two oral BA values. Additionally, the speed of effect-onset and the significantly improved $\mathrm{T}_{\max }$ fits the necessary parameters for acute pain relief and closely mimics intravenous administration [16].

\begin{tabular}{|c|c|c|c|c|c|c|c|c|}
\hline $\begin{array}{l}\text { Time } \\
(\min .)\end{array}$ & Oral (ng/mL) & $\begin{array}{l}\text { Oral Area (ng } \cdot \mathrm{min} / \\
\mathrm{mL})\end{array}$ & $\begin{array}{c}\mathrm{IN}-1 \\
(\mathrm{ng} / \mathrm{mL})\end{array}$ & IN -1 Area $(\mathrm{ng} \cdot \mathrm{min} / \mathrm{mL})$ & IN-2 (ng/mL) & $\begin{array}{l}\text { IN-2 Area (ng } \cdot \mathrm{min} / \\
\mathrm{mL})\end{array}$ & $\begin{array}{c}\mathrm{IN}-3 \\
(\mathrm{ng} / \mathrm{mL})\end{array}$ & $\begin{array}{c}\text { IN-3 Area } \\
\text { (ng } \cdot \mathrm{min} / \mathrm{mL})\end{array}$ \\
\hline 0 & 0 & \multirow{11}{*}{$\begin{array}{c}0 \\
0 \\
0 \\
0 \\
0 \\
0 \\
5.5 \\
39 \\
81 \\
72\end{array}$} & 0 & \multirow{11}{*}{$\begin{array}{c}0 \\
2.125 \\
5 \\
5.875 \\
11 \\
9.25 \\
16.5 \\
43.5 \\
69 \\
60\end{array}$} & 0 & \multirow{11}{*}{$\begin{array}{c}0 \\
7.5 \\
12.25 \\
14.125 \\
26 \\
21.5 \\
33 \\
63 \\
75 \\
60\end{array}$} & 0 & \multirow{11}{*}{$\begin{array}{c}0 \\
10.25 \\
15.25 \\
16.375 \\
32.5 \\
29.75 \\
51.5 \\
112.5 \\
129 \\
96\end{array}$} \\
\hline 2.5 & 0 & & 0 & & 1.8 & & 2.5 & \\
\hline 5 & 0 & & 1.7 & & 4.2 & & 5.7 & \\
\hline 7.5 & 0 & & 2.3 & & 5.6 & & 6.5 & \\
\hline 10 & 0 & & 2.4 & & 5.7 & & 6.6 & \\
\hline 15 & 0 & & 2 & & 4.7 & & 6.4 & \\
\hline 20 & 0 & & 1.7 & & 3.9 & & 5.5 & \\
\hline 30 & 1.1 & & 1.6 & & 2.7 & & 4.8 & \\
\hline 60 & 1.5 & & 1.3 & & 1.5 & & 2.7 & \\
\hline 120 & 1.2 & & 1 & & 1 & & 1.6 & \\
\hline \multirow[t]{4}{*}{240} & 0 & & 0 & & 0 & & 0 & \\
\hline & $\begin{array}{c}\text { Total area } \\
\text { under curve }\end{array}$ & 197.5 & & 222.25 & & 312.375 & 0 & 493.125 \\
\hline & Relative BA & 1.00 & & 1.13 & & 1.58 & & 2.50 \\
\hline & $\begin{array}{l}\text { Extrapolated BA } \\
\text { from average }\end{array}$ & $37.5 \%$ & & $42 \%$ & & $59 \%$ & & $94 \%$ \\
\hline
\end{tabular}

Table 2: Comparison of AUC of oral hydromorphone vs. 3 formulations of intranasal hydromorphone. Bioavailability was extrapolated based on average BA literature derived reports of oral hydromorphone $[14,15]$. 
Citation: Cunningham G, Maggio ET (2018) Non-Invasive Nasal Hydromorphone with High Bioavailability for Rapid Onset and Non-Dissociative Acute Pain Control: A Feasibility Study. J Bioequiv Availab 10: 014-017. doi: 10.4172/jbb.1000369

\section{Discussion}

The alkylsaccharide-based based IN-3 formulation exhibits a rapid onset of drug action (approximately $1 \mathrm{~min}$. with a $\mathrm{T}_{\max }$ of 7.5 min.) and high systemic bioavailability (approximately $90 \%$ relative to oral administration). This is consistent with results obtained with similar sized drugs where alkylsaccharides were incorporated into the nasal formulation to enhance bioavailability $[9,10]$. The study wasn't designed to measure inter-subject $\mathrm{CV}$, but rather to test the hypothesis that hydromorphone administration via intranasal route could effectively mimic IV administration parameters. While the results point to the likely utility of alkylsaccharide-based formulations of hydromorphone, it would be improper to draw any firm conclusions about the likely performance in formal clinical studies conducted with a generalized population. Nevertheless, this pilot study suggests that alkylsaccharide-based metered nasal spray formulations of hydromorphone may offer the best pharmacokinetic performance of any non-IV preparations, while still meeting the clinical parameters found in IV administration.

\section{Conclusion}

The limitations of this $\mathrm{n}=1$ study is clearly recognized, however in light of the similar BA results obtained with other drugs having similar molecular weights, based on the study findings, we believe the proprietary formulations of intranasal hydromorphone utilizing Intravail ${ }^{\circ}$ alkylsaccharide excipient should be further investigated and developed. The ability to deliver hydromorphone without venous access would provide a breakthrough in achieving rapid pain control without dissociative effects and would represent a major step forward in meeting the pain control limitations of current medication practice.

\section{References}

1. Arnold JJ, Ahsan F, Meezan E, Pillion DJ (2004) Correlation of tetradecylmaltoside induced increases in nasal peptide drug delivery with morphological changes in nasal epithelial cells. J Pharm Sci 93: 2205-2213.

2. Maggio ET (2014) Absorption enhancing excipients in systemic nasal drug delivery. J Excip Food Chem 5:1-13.
3. eHealthme: Personalised Health Information (2017) Dilaudid and Vasoconstriction: From FDA Reports.

4. Maggio ET, Pillion DJ (2013) High efficiency intranasal drug delivery using intravail alkylsaccharide absorption enhancers. Drug Deliv and Transl Res 3: 16-25.

5. Weber N, Benning $\mathrm{H}$ (1984) Metabolism of orally administered alkyl glycosides. J Nutrition 114: 246-254.

6. Ahsan F, Arnold JJ, Yang T, Meezan E, Schwiebert EM, et al. (2003) Effects of the permeability enhancers, tetradecylmaltoside and dimethyl-b-17 cyclodextrin, on insulin movement across human bronchial epithelial cells (16HBE140-). Eur J Pharm Sci 20: 27-34.

7. Yang T, Mustafa F, Bai S, Ahsan F (2005) Pulmonary delivery of low molecular weight heparins. J Drug Targeting 13: 29-38.

8. Arnold JJ, Ahsan F, Meezan E, Pillion DJ (2002) Nasal administration of low molecular weight heparin. J Pharm Sci 91: 1707-1714.

9. Agarwal SK, Kriel RL, Brundagea RC, Ivaturi VD, Cloyd (2013) A pilot study assessing the bioavailability and pharmacokinetics of diazepam after intranasal and intravenous administration in healthy volunteers. Epilepsy Research 105 : 362-367.

10. Munjal S, Gautam A, Offman E, Brand-Schieber E, Allenby K, et al. (2016) A randomized trial comparing the pharmacokinetics, safety, and tolerability of DFN-02, an intranasal sumatriptan spray containing a permeation enhancer, with intranasal and subcutaneous sumatriptan in healthy adults. Headache 56: 1455-1465.

11. Comparison of patient ratings of hydromorphone and fentanyl at Drugs.com

12. Rudy AC, Coda BA, Archer SM, Wermeling DP (2004) A multiple-dose phase I study of intranasal hydromorphone hydrochloride in healthy volunteers. Anesth Analg 99: 1379-1386.

13. NMS Labs (2018) Hydromorphone assay details: Hydromorphone: Free (unconjugated), serum/plasma test (8664sp).

14. Parab PV, Ritschel WA, Coyle DE, Gregg RV, Denson DD (1998) Pharmacokinetics of hydromorphone after intravenous, peroral and rectal administration to human subjects. Biopharmaceutics and Drug Disposition 9 (2): 187-199.

15. Medication Guide approved by the U.S. FDA (2016) DILAUDID: Hydromorphone hydrochloride tablet.

16. Hill HF, Coda BA, Tanaka A, Schaffer R (1991) Multiple-dose evaluation of intravenous hydromorphone pharmacokinetics in normal human subjects. Anesth Analg 72: 330-336. 